\title{
Role of Presepsin for the Diagnosis of Sepsis and ICU Mortality: A Prospective Controlled Study
}

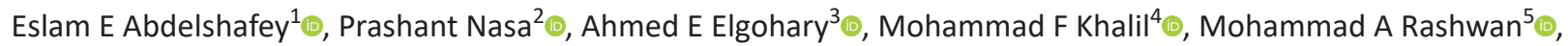 \\ Hassen B Ghezala ${ }^{6}$, Ashraf A Tayar $^{7}$ (1)
}

\begin{abstract}
Background: This study aimed at evaluating the role of presepsin in early identification of sepsis and prediction of mortality in intensive care unit (ICU) patients in comparison to systemic inflammatory response syndrome (SIRS) and quick sequential organ failure assessment (qSOFA) score.

Materials and methods: Forty patients were selected randomly after admission to adult ICU. Data from emergency room (ER) triaging, and initial laboratory results were gathered to calculate qSOFA score, SIRS criteria, and SOFA score. Presepsin measurement was performed within 6 hours from ER triaging.

The patients were categorized into sepsis and nonsepsis groups depending on the clinical and microbiological criteria and SOFA score changes. Results: Twenty-six patients were diagnosed as septic with an average age of $68.04 \pm 18.60$ years, while 14 patients were nonseptic with an average age of $51.71 \pm 24.88$ years.

Presepsin with a cutoff value $>640 \mathrm{pg} / \mathrm{mL}$ (area under the curve [AUC] of $0.848\{p<0.001\}$ ) had a significant diagnostic accuracy of identifying septic cases with sensitivity of $73.08 \%$ and specificity of $92.86 \%$ as compared to the nonsignificant SIRS (AUC, 0.670 ; sensitivity, $69.23 \%$; and specificity, 57.14\%) or qSOFA (AUC, 0.652; sensitivity, 38.46\%; and specificity, 78.57\%) criteria.

Prespsin with a cutoff value $>640 \mathrm{pg} / \mathrm{mL}$ also significantly (AUC of $0.920[p<0.001]$ ) predicted mortality with sensitivity of $100.0 \%$ and specificity of $66.67 \%$ compared to the nonsignificant SIRS (AUC, 0.540; sensitivity, 70.0\%; and specificity, 43.33\%) or qSOFA (AUC, 0.670; sensitivity, 60\%; and specificity, $76.67 \%)$ criteria.

Conclusion: Early presepsin measurement in ICU patients is more accurate in the diagnosis of sepsis and prediction of mortality as compared to SIRS or qSOFA score.

Keywords: Biomarkers, Presepsin, Predictive model, qSOFA: quick sequential (sepsis-related) organ failure assessment, Sepsis.

Indian Journal of Critical Care Medicine (2021): 10.5005/jp-journals-10071-23715
\end{abstract}

\section{INTRODUCTION}

The timely diagnosis of sepsis is challenging, despite its high morbidity and mortality. ${ }^{1}$ There are numerous clinical and biological markers being tested for early diagnosis of sepsis. The task force comprising global experts coined revised definition on sepsis (Sepsis 3) in which the conventional systemic inflammatory response syndrome (SIRS) criteria was replaced by the sequential organ failure assessment (SOFA) score for the diagnosis of sepsis. ${ }^{2}$ A quick SOFA (qSOFA) score was also advocated as a bedside tool to facilitate the early identification of patients potentially at risk of dying from sepsis, especially outside intensive care unit (ICU). ${ }^{3}$

Presepsin is a novel biological marker produced by the cleavage of the N-terminal of soluble CD14 (sCD14). ${ }^{4}$ CD14 is a member of Toll-like receptor (TLR) and acts as a coreceptor for various ligands from both gram-positive and gram-negative bacteria (GNB). Lipopolysaccharide (LPS) complex of GNB is the most-studied ligand and in association with LPS-binding protein (LBP) and CD14 binds to TLR. ${ }^{4,5}$ LPS-LBP-CD14-TLR complex formation on the effector cells (like monocytes and macrophages), causes activation and then contributes to the intracellular signaling and production of cytokines, triggering the initial host inflammatory response against the pathogen. CD14 are of two types: membrane-bound CD14 (mCD14) and soluble CD14 (sCD14). mCD14 is involved in ligand
${ }^{1}$ Department of Critical Care Medicine, Alexandria, Egypt

${ }^{1,3-7}$ Department of Intensive Care Unit, Security Forces Hospital, Dammam, Saudi Arabia

${ }^{2}$ Department of Critical Care Medicine, NMC Specialty Hospital, Dubai, United Arab Emirates

Corresponding Author: Prashant Nasa, Department of Critical Care Medicine, NMC Specialty Hospital, Dubai, United Arab Emirates, Phone: +971 501425022, e-mail: dr.prashantnasa@hotmail.com

How to cite this article: Abdelshafey EE, Nasa P, Elgohary AE, Khalil MF, Rashwan MA, Ghezala HB, et al. Role of Presepsin for the Diagnosis of Sepsis and ICU Mortality: A Prospective Controlled Study. Indian J Crit Care Med 2021;25(2):153-157.

Source of support: Nil

Conflict of interest: None

binding and SCD14 is released into the plasma either by the effector cells or by the fall-off from mCD14. ${ }^{5}$ Presepsin is thus, a biomarker of activated innate immune system to invading pathogen.

We undertook this study, to evaluate the significance of presepsin for early identification of sepsis and prediction of ICU mortality in comparison to the SIRS criteria and the qSOFA score.

\footnotetext{
() Jaypee Brothers Medical Publishers. 2021 Open Access This article is distributed under the terms of the Creative Commons Attribution 4.0 International License (https://creativecommons.org/licenses/by-nc/4.0/), which permits unrestricted use, distribution, and non-commercial reproduction in any medium, provided you give appropriate credit to the original author(s) and the source, provide a link to the Creative Commons license, and indicate if changes were made. The Creative Commons Public Domain Dedication waiver (http://creativecommons.org/publicdomain/zero/1.0/) applies to the data made available in this article, unless otherwise stated.
} 


\section{Materials and Methods}

\section{Data Collection}

Between June 2018 and December 2018, 40 adult patients ( $\geq 18$ years) were randomly selected after admission to ICU from ER. The demographic data on age, sex, and acute physiology and chronic health evaluation II score (APACHE II) were collated.

The data on initial mental status using Glasgow coma score (GCS), systolic blood pressure (SBP), and respiratory rate (RR) were taken from ER to calculate the qSOFA score. The temperature, RR, heart rate (HR), and white blood cell (WBC) count were used to calculate SIRS. qSOFA was defined by Sepsis 3, 2016 criteria altered mentation (GCS $<15$ ), SBP $<100 \mathrm{mmHg}$, and RR $\geq 22$ breaths $/ \mathrm{min}^{3}{ }^{3}$ SIRS was defined as HR $>90$ beats $/ \mathrm{min}, \mathrm{RR}>20$ breaths $/ \mathrm{min}$ temperature $>38$ or $<36^{\circ} \mathrm{C}$, and WBC $>12,000 / \mathrm{mm}^{3}$ or $<4000 / \mathrm{mm}^{3}$ or band cells $\geq 10 \%$.

SOFA score was calculated once all the laboratory parameters (serum bilirubin, platelet count, serum creatinine, and arterial blood gas) were available and within 6 hours of triaging in ER. Presepsin measurement in full blood sample was also performed within 6 hours from triaging using PATHFAST 1602D2600 from LSI Medience Corporation, Japan. This is a point-of-care (POC), highly sensitive, and fully automated chemiluminescent enzyme immunoassay-based measurement system that provides its result within 17 minutes. ${ }^{6}$

The diagnosis of sepsis was made when patients revealed a microbiologically or clinically proven infection with at least one new organ dysfunction assessed by the change of a SOFA score $\geq 2$; otherwise patients are claimed to be nonseptic. Comparison of sepsis and nonsepsis groups was done for age, sex, APACHE II, SOFA, qSOFA, SIRS, and presepsin levels.

\section{Statistical Analysis}

The continuous variables were expressed as means \pm standard deviation (SD), medians, and interquartile ranges (minimummaximum). The categorical variables were expressed in counts and percentages. Clinical comparison between sepsis and nonsepsis group was done using two-sample T-test and Mann-Whitney test for continuous variables, and chi-square test and Fisher exact test for categorical variables. Receiver operating characteristic (ROC) curves were plotted and areas under the ROC curve (AUC) were calculated using Youden index for the diagnostic accuracy of presepsin, qSOFA, SIRS, and the combination of presepsin with qSOFA or SIRS for sepsis and ICU mortality. Based on the optimal cutoff values of presepsin for discriminating between the two groups of sepsis and nonsepsis, according to the ROC curve analysis, the sensitivity, specificity, positive predictive value (PPV), and negative predictive value (NPV) were also calculated. $p$-value less than 0.05 was taken as significant. IBM SPSS (version 20.0, Armonk, NY: IBM Corp.) was used for analysis.

\section{Aims and Objectives}

Primary:

- To compare presepsin to SIRS and qSOFA for the diagnosis of sepsis.

- To compare presepsin to SIRS and qSOFA for predicting ICU mortality in sepsis patients.

Secondary:

- To identify the optimal cutoff for presepsin for the diagnosis and ICU mortality in sepsis.

\section{Results}

Out of 40 patients included in the study, 26 (65\%) patients were diagnosed as septic and 14 (35\%) patients were nonseptic. The average age was significantly higher in sepsis group as compared to nonsepsis (mean $68.04 \pm 18.60$ vs $51.71 \pm 24.88$ years, $p=0.024$ ) while no significant difference was found regarding sex (males 61.5 vs $57.1 \%$, respectively, $p=0.787$ ). Patients in the sepsis group were significantly sick with an average APACHE II score (18.50 \pm 6.13 vs $13.36 \pm 7.53, p=0.029$ ) higher than the nonsepsis group. Similarly, the SOFA score was also significantly higher in the sepsis group (mean of $5.81 \pm 3.41$ vs $2.86 \pm 4.37, p=0.001$ ) (Table 1 ). No significant

Table 1: Comparison between the two groups based on baseline characteristics and studied sepsis scale

\begin{tabular}{|c|c|c|c|}
\hline & Sepsis $(n=26)$ & No sepsis $(n=14)$ & $p$-value \\
\hline \multicolumn{4}{|l|}{$\operatorname{Sex}(n(\%)$} \\
\hline Male & $16(61.5)$ & $8(57.1)$ & \\
\hline Female & $10(38.5)$ & $6(42.9)$ & \\
\hline \multicolumn{4}{|l|}{ Age (in years) } \\
\hline Median (range) & $72.50(20.0-89.0)$ & $45.0(15.0-86.0)$ & \\
\hline Mean (SD) & $68.04(18.60)$ & $51.71(24.88)$ & \\
\hline \\
\hline & \multicolumn{3}{|c|}{ Scale } \\
\hline Median (range) & $14.5(4.0-15.0)$ & $15.0(3.0-15.0)$ & \\
\hline Mean (SD) & $12.19(3.48)$ & $13.50(3.70)$ & \\
\hline \multicolumn{4}{|l|}{$\begin{array}{l}\text { Heart rate } \\
\text { (beats/minute) }\end{array}$} \\
\hline Median (range) & $97.0(66.0-130.0)$ & $93.50(58.0-117.0)$ & \\
\hline Mean (SD) & $95.50(15.53)$ & $91.0(20.11)$ & \\
\hline \multicolumn{4}{|l|}{$\begin{array}{l}\text { Respiratory rate } \\
\text { (per minute) }\end{array}$} \\
\hline Median (range) & $22.0(16.0-32.0)$ & $20(8.0-26.0)$ & \\
\hline Mean (SD) & $22.35(3.74)$ & $19.79(4.85)$ & \\
\hline \multicolumn{4}{|c|}{$\begin{array}{l}\text { Systolic blood } \\
\text { pressure }(\mathrm{mm} \mathrm{Hg})\end{array}$} \\
\hline Median (range) & $117.0(84.0-154.0)$ & $133.5(100.0-165.0)$ & \\
\hline Mean (SD) & $119.5(19.04)$ & $129.4(21.64)$ & \\
\hline \multicolumn{4}{|l|}{$\begin{array}{l}\text { Temp } \\
\text { (degree celsius) }\end{array}$} \\
\hline Median (range) & $36.90(34.50-38.50)$ & $36.90(36.80-39.0)$ & \\
\hline Mean (SD) & $36.95(0.71)$ & $37.24(0.63)$ & \\
\hline \multicolumn{4}{|l|}{$\begin{array}{l}\text { White blood cells } \\
\left(\times 10^{3} / \mathrm{mm}^{3}\right)\end{array}$} \\
\hline Median (range) & $14.75(2.0-37.10)$ & $10.60(3.89-19.40)$ & \\
\hline Mean (SD) & $16.41 \pm 9.32$ & $10.26 \pm 4.46$ & \\
\hline \multicolumn{4}{|l|}{ APACHE II } \\
\hline Median (range) & $17.50(11.0-38.0)$ & $12.0(0.0-26.0)$ & $0.029^{*}$ \\
\hline Mean (SD) & $18.50(6.13)$ & $13.36(7.53)$ & \\
\hline \multicolumn{4}{|l|}{ SOFA } \\
\hline Median (range) & $5.0(2.0-14.0)$ & $1.50(2.86 \pm 4.37)$ & $0.001^{*}$ \\
\hline Mean (SD) & $5.81(3.41)$ & $2.86(4.37)$ & \\
\hline \multicolumn{4}{|l|}{ qSOFA } \\
\hline Median (range) & $1.0(0.0-3.0)$ & $0.50(0.0-2.0)$ & 0.096 \\
\hline Mean (SD) & $1.19(0.85)$ & $0.71(0.83)$ & \\
\hline \multicolumn{4}{|l|}{ SIRS } \\
\hline Median (range) & $2.0(0.0-4.0)$ & $1.0(0.0-3.0)$ & 0.068 \\
\hline Mean (SD) & $2.0(1.02)$ & $1.36(1.01)$ & \\
\hline
\end{tabular}

*Statistically significant at $p \leq 0.05$; SOFA, sequential organ failure assessment; qSOFA, quick SOFA; SIRS, systemic inflammatory response syndrome; APACHE II, acute physiological and chronic health evaluation II score 
difference was found between the groups in relation to all the elements of qSOFA score and the complete score itself (mean qSOFA of $1.19 \pm 0.85$ in sepsis vs $0.71 \pm 0.83$ in nonsepsis group, $p=0.096$ ) (Table 1). SIRS elements were also not significantly different between the groups for temperature, RR, or HR except WBC count which was higher in sepsis group (mean value of $16.41 \pm 9.32$ vs $10.26 \pm 4.46$ $\left[\times 10^{3} \mathrm{cell} / \mathrm{mm}^{3}\right], p=0.0370$ ) (Table 1). Overall, the SIRS criteria was also not significantly different between the groups (mean of $2.0 \pm 1.02$ in sepsis vs $1.36 \pm 1.01$ in nonsepsis group, $p=0.068$ ) (Table 1 ).

Presepsin levels were significantly higher in the sepsis group (mean of $2726.5 \pm 3930.3 \mathrm{pg} / \mathrm{mL}$ vs $414.6 \pm 445.9 \mathrm{pg} / \mathrm{mL}, p<0.001$ ) as compared to the nonsepsis group. The ICU mortality was also higher in the sepsis group (34.6\%) as compared to the nonsepsis group $(7.1 \%)(p=0.07)$ (Table 2$)$.

The comparison of qSOFA, SIRS criteria and presepsin for early identification of septic cases was done using the ROC curve analysis. Presepsin alone has a significantly higher accuracy (AUC of 0.848 , $p<0.001$ ) with sensitivity of $73.08 \%$ and specificity of $92.86 \%$ for the diagnosis of sepsis, and the cutoff value for presepsin was $640 \mathrm{pg} / \mathrm{mL}$. At this cutoff value, the addition of presepsin to qSOFA has a better accuracy than qSOFA alone (AUC of 0.838 vs 0.652 and $p$-value $<0.001$ vs 0.116 , respectively). The addition of presepsin to SIRS also increases the diagnostic accuracy as compared to the SIRS alone (AUC of 0.849 vs 0.670 and $p$-value $<0.001$ vs 0.079 , respectively) (Fig. 1, Table 3 ).

Comparing the significance of qSOFA score, SIRS criteria, and presepsin for early prediction of ICU mortality was done also using the ROC curve analysis. Presepsin levels had a significantly higher prediction ability (AUC of $0.920, p<0.001$ ) for ICU mortality with a sensitivity of $100.0 \%$, specificity of $66.67 \%$, and a cutoff value

Table 2: Comparison between the two studied groups according to presepsin value $(\mathrm{pg} / \mathrm{mL})$ and ICU mortality

\begin{tabular}{|c|c|c|c|c|}
\hline & $\begin{array}{l}\text { Sepsis } \\
(n=26)\end{array}$ & $\begin{array}{l}\text { No sepsis } \\
(n=14)\end{array}$ & Test of sig. & $p$-value \\
\hline \multicolumn{5}{|l|}{$\begin{array}{l}\text { Presepsin } \\
(\mathrm{pg} / \mathrm{mL})\end{array}$} \\
\hline Min.-Max. & 163.0-19370.0 & $38.40-1795.0$ & & \\
\hline Mean \pm SD & $2726.5 \pm 3930.3$ & $414.6 \pm 445.9$ & $U=55.50$ & $<0.001^{*}$ \\
\hline \multirow[t]{2}{*}{ Median } & 1311.5 & 349.0 & & \\
\hline & No. & No. & & \\
\hline ICU mortality & 34.6 & 7.1 & $\chi^{2}=3.663$ & 0.070 \\
\hline
\end{tabular}

*Statistically significant at $p \leq 0.05 ; \chi^{2}$, Chi-square test; $U$ : Mann-Whitney test; ICU, intensive care unit of $640 \mathrm{pg} / \mathrm{mL}$. The addition of presepsin to qSOFA increases the prediction accuracy of ICU mortality as compared to qSOFA alone (AUC of 0.917 vs 0.670 and $p$-value of $<0.001$ vs 0.111 , respectively). The combination of presepsin to SIRS also has a significantly higher prediction accuracy for ICU mortality than SIRS alone (AUC of 0.920 vs 0.540 and $p$-value of $<0.001$ vs 0.708 , respectively) (Fig. 2, Table 4).

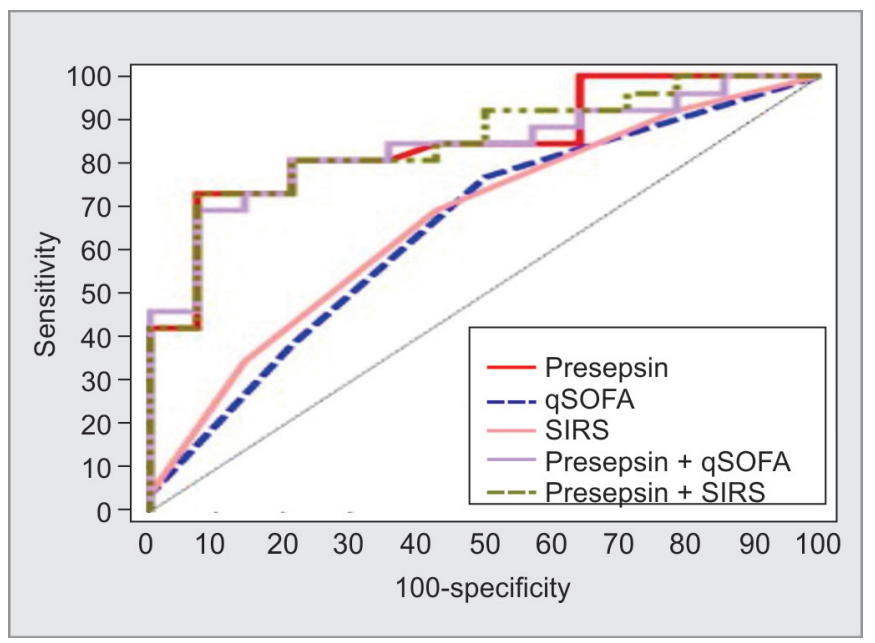

Fig. 1: Receiver-operating characteristics for diagnosis of sepsis

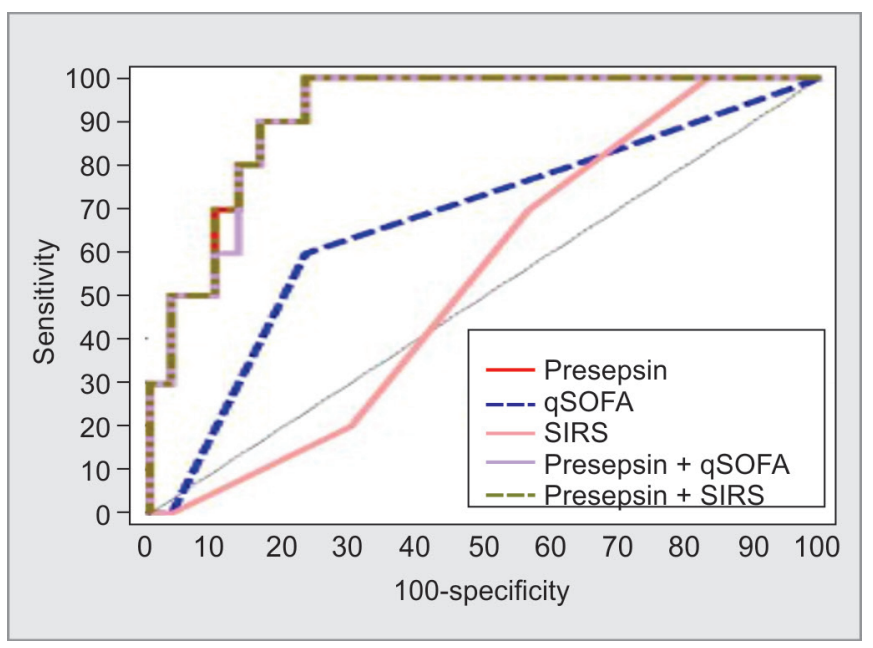

Fig. 2: Receiver-operating characteristics for prediction of ICU mortality

Table 3: Diagnostic accuracy for presepsin, qSOFA, SIRS, presepsin + qSOFA, and presepsin + SIRS in sepsis patients

\begin{tabular}{|c|c|c|c|c|c|c|c|c|c|}
\hline & \multirow[b]{2}{*}{ AUC } & \multirow[b]{2}{*}{$p$-value } & \multicolumn{2}{|c|}{$95 \% \mathrm{Cl}$} & \multirow[b]{2}{*}{ Cutoff $^{\#}$} & \multirow[b]{2}{*}{ Sensitivity } & \multirow[b]{2}{*}{ Specificity } & \multirow[b]{2}{*}{$P P V$} & \multirow[b]{2}{*}{$N P V$} \\
\hline & & & $L L$ & $U L$ & & & & & \\
\hline Presepsin & 0.848 & $<0.001^{*}$ & 0.727 & 0.968 & $>640$ & 73.08 & 92.86 & 95.0 & 65.0 \\
\hline qSOFA & 0.652 & 0.116 & 0.472 & 0.833 & $\geq 2$ & 38.46 & 78.57 & 76.92 & 40.74 \\
\hline SIRS & 0.670 & 0.079 & 0.495 & 0.846 & $\geq 2$ & 69.23 & 57.14 & 75.0 & 50.0 \\
\hline Presepsin + qSOFA & 0.838 & $<0.001^{*}$ & 0.715 & 0.961 & - & 76.92 & 78.57 & 86.96 & 64.71 \\
\hline Presepsin + SIRS & 0.849 & $<0.001^{*}$ & 0.729 & 0.969 & - & 80.77 & 71.43 & 84.0 & 66.67 \\
\hline
\end{tabular}

"Cutoff was done by using Youden index; *Statistically significant at $p \leq 0.05$; AUC, area under the curve; LL, lower limit; UL, upper limit; PPV, positive predictive value; NPV, negative predictive value; $\mathrm{Cl}$, confidence interval; qSOFA, quick sequential organ failure assessment; SIRS, systemic inflammatory response syndrome 
Table 4: Agreement (sensitivity, specificity) for presepsin, qSOFA, SIRS, presepsin + qSOF, and presepsin + SIRS for prediction of ICU mortality

\begin{tabular}{|c|c|c|c|c|c|c|c|c|c|}
\hline & \multirow[b]{2}{*}{$A \cup C$} & \multirow[b]{2}{*}{$p$-value } & \multicolumn{2}{|c|}{$95 \% \mathrm{Cl}$} & \multirow[b]{2}{*}{ Cutoff $^{\#}$} & \multirow[b]{2}{*}{ Sensitivity } & \multirow[b]{2}{*}{ Specificity } & \multirow[b]{2}{*}{ PPV } & \multirow[b]{2}{*}{ NPV } \\
\hline & & & $L L$ & $U L$ & & & & & \\
\hline Presepsin & 0.920 & $<0.001^{*}$ & 0.838 & 1.00 & $>640$ & 100.0 & 66.67 & & 100.0 \\
\hline qSOFA & 0.670 & 0.111 & 0.469 & 0.871 & $\geq 2$ & 60.0 & 76.67 & 46.15 & 85.19 \\
\hline SIRS & 0.540 & 0.708 & 0.357 & 0.723 & $\geq 2$ & 70.0 & 43.33 & 29.17 & 81.25 \\
\hline Presepsin + qSOFA & 0.917 & $<0.001^{*}$ & 0.833 & 1.00 & - & 50.0 & 93.33 & 71.43 & 84.85 \\
\hline Presepsin + SIRS & 0.920 & $<0.001^{*}$ & 0.838 & 1.00 & - & 50.0 & 93.33 & 71.43 & 84.85 \\
\hline
\end{tabular}

"Cutoff was done by using Youden index; *Statistically significant at $p \leq 0.05$; AUC, area under the curve; LL, lower limit; UL, upper limit; PPV, positive predictive value; NPV, negative predictive value; $\mathrm{Cl}$, confidence interval; qSOFA, quick sequential organ failure assessment; SIRS, systemic inflammatory response syndrome

\section{Discussion}

Early identification and timely treatment especially with antimicrobials is associated with reduced mortality in sepsis. ${ }^{7}$ The bedside clinical screening tools (SIRS and qSOFA) were aimed at recognizing sepsis early and predicting patients with higher risk of mortality. ${ }^{2,3}$ These traditional tools are either only sensitive (SIRS) or specific (qSOFA) for an organ dysfunction but overall have a poor discrimination ability to diagnose sepsis. ${ }^{8}$

Sepsis is a life-threatening organ dysfunction due to a dysregulated host-immune response. Innate immune system is the primary human barrier to bacterial infection, and presepsin is a biological marker representing its activation. ${ }^{4}$ In our study, presepsin (cutoff $640 \mathrm{pg} / \mathrm{mL}$ [AUC 0.848 and $p=<0.001$ ]) could accurately differentiate sepsis patients from nonsepsis patients with a remarkable sensitivity and specificity of 73.08 and $92.86 \%$, respectively (Table 3 ). Endo et al., in their study showed that presepsin can discriminate bacterial infections from nonbacterial infectious diseases with a cutoff value of $600 \mathrm{pg} / \mathrm{mL}$ (AUC of 0.908 ) and a sensitivity and specificity of 87.8 and $81.4 \%$, respectively. ${ }^{9}$ In a metanalysis of eight studies with over 1800 patients using the older definition of sepsis, presepsin showed a similar diagnostic accuracy (AUC $=0.89$ ) for the diagnosis of sepsis. ${ }^{10}$ The diagnostic performance of SIRS and qSOFA was very modest compared to the presepsin alone with an AUC of 0.670 and 0.652 , respectively, and the addition of presepsin to these clinical scores increased the diagnostic yield of each of them significantly (AUC of 0.838 and 0.849 , respectively, $p=<0.001$ ) (Table 3).

The prognostic performance in the prediction of ICU mortality of presepsin (cutoff $640 \mathrm{pg} / \mathrm{mL}$ [AUC 0.920 and $p=<0.001$ ]) was also significantly better as compared to the SIRS and qSOFA alone (AUC 0.670 and 0.540 , respectively). The addition of presepsin level to SIRS and qSOFA increased their prognostic performance significantly (AUC of 0.917 and 0.920 , respectively, $p=<0.001$ ). This is consistent with a post hoc analysis of albumin Italian outcome sepsis (ALBIOS) trial, which showed a higher level of presepsin on day 1 among survivors as compared to survivors with a level of $2269 \mathrm{pg} / \mathrm{ml}$ and $1184 \mathrm{pg} / \mathrm{ml}$, respectively. ${ }^{11}$ In a metanalysis of 10 studies with 1617 patients, presepsin collected within the first 24 hours was significantly different between survivors and nonsurvivors (AUC of $0.92, p=<0.01$ ) on a random-effect model. ${ }^{12}$

In our study, presepsin showed a higher accuracy of sepsis diagnosis and ICU mortality than many previous studies. This may be related to inclusion of random cases and also may be early measurement of presepsin level within 6 hours of hospital admission.

The strength of our study is that it is a prospective, controlled study with direct comparison of POC presepsin with the bedside clinical tools in the diagnosis and prognosis of sepsis. We also found that combination of presepsin with these tools can improve their diagnostic accuracy and prediction of outcome. There are a few limitations to our study: the small number of cases, the random selection of patients because of shortage of laboratory reagent for presepsin which may have caused some bias, and also the lack of comparison to other sepsis biomarkers.

\section{Conclusion}

Presepsin at a cutoff of $640 \mathrm{ng} / \mathrm{mL}$ is an accurate tool for diagnosing and prognosticating sepsis. qSOFA and SIRS when combined with POC presepsin can accurately detect sepsis as compared to when used alone.

\section{OrCID}

Eslam E Abdelshafey (10 https://orcid.org/0000-0001-8018-2948

Prashant Nasa 이 https://orcid.org/0000-0003-1948-4060

Ahmed E Elgohary (1) https://orcid.org/0000-0002-8230-6200

Mohammad F Khalil @ i https://orcid.org/0000-0001-7816-8610

Mohammad A Rashwan (ㄴ) https://orcid.org/0000-0001-8987-0034

Hassen B Ghezala 이 https://orcid.org/0000-0002-7083-7303

Ashraf A Tayar (10 https://orcid.org/0000-0002-2897-7417

\section{References}

1. Fleischmann C, Scherag A, Adhikari NK, Hartog CS, Tsaganos T, Schlattmann $P$, et al. Assessment of global incidence and mortality of hospital-treated sepsis. Current estimates and limitations. Am J Respir Crit Care Med 2016;193(3):259-272. DOI: 10.1164/rccm.201504-07810C.

2. Singer $M$, Deutschman CS, Seymour CW, Shankar-Hari M, Annane $D$, Bauer $M$, et al. The third international consensus definitions for sepsis and septic shock (Sepsis-3). JAMA 2016;23;315(8):801-810. DOI: 10.1001/jama.2016.0287.

3. Seymour CW, Liu VX, Iwashyna TJ, Brunkhorst FM, Rea TD, Scherag A, et al. Assessment of clinical criteria for sepsis: for the third international consensus definitions for sepsis and septic shock (Sepsis-3). [Published correction appears in JAMA 2016;315(20):2237]. JAMA 2016;315(8):762-774. DOI: 10.1001/jama.2016.0288.

4. Chenevier-Gobeaux C, Borderie D, Weiss N, Mallet-Coste T, Claessens YE. Presepsin (sCD14-ST), an innate immune response marker in sepsis. Clin Chim Acta 2015;450:97-103. DOI: 10.1016/j. cca.2015.06.026. 
5. Memar MY, Baghi HB. Presepsin: a promising biomarker for the detection of bacterial infections. Biomed Pharmacother 2019;111:649-656. DOI: 10.1016/j.biopha.2018.12.124.

6. Okamura Y, Yokoi H. Development of a point-of-care assay system for measurement of presepsin (sCD14-ST). Clin Chim Acta 2011;412(23-24):2157-2161. DOI: 10.1016/j.cca.2011.07.024.

7. Seymour CW, Gesten F, Prescott HC, Friedrich ME, Iwashyna TJ, Phillips GS, et al. Time to treatment and mortality during mandated emergency care for sepsis. N Engl J Med 2017;376(23):2235-2244. DOI: 10.1056/NEJMoa1703058.

8. Marik PE, Taeb AM. SIRS, qSOFA and new sepsis definition. J Thorac Dis 2017;9(4):943-945. DOI: 10.21037/jtd.2017.03.125.

9. Endo S, Suzuki Y, Takahashi G, Shozushima T, Ishikura H, Murai A, et al. Usefulness of presepsin in the diagnosis of sepsis in a multicenter prospective study. J Infect Chemother 2012;18(6):891-897. DOI: 10.1007/s10156-012-0435-2.

10. Zhang X, Liu D, Liu YN, Wang R, Xie LX. The accuracy of presepsin (sCD14-ST) for the diagnosis of sepsis in adults: a meta-analysis. Crit Care 2015;19(1):323. DOI: 10.1186/s13054-015-1032-4.

11. Masson S, Caironi P, Spanuth E, Thomae R, Panigada M, Sangiorgi G, et al. Presepsin (soluble CD14 subtype) and procalcitonin levels for mortality prediction in sepsis: data from the Albumin Italian Outcome Sepsis trial. Crit Care 2014;18(1):R6. DOI: $10.1186 / \mathrm{cc} 13183$.

12. Yang HS, Hur M, Yi A, Kim H, Lee S, Kim SN. Prognostic value of presepsin in adult patients with sepsis: systematic review and meta-analysis. PLoS One 2018;13(1):e0191486. DOI: 10.1371/journal. pone. 0191486. 